Pacific Journal of Mathematics

INTERPOLATING SEQUENCES FOR FUNCTIONS SATISFYING 


\title{
INTERPOLATING SEQUENCES FOR FUNCTIONS SATISFYING A LIPSCHITZ CONDITION
}

\author{
ERIC P. KRONSTADT
}

Let $D$ be the unit disk in $C$, Lip $(D)$ the space of functions, $f$, holomorphic in $D$, continuous on $\bar{D}$ and satisfying a Lipschitz condition:

$$
|f(z)-f(w)| \leqq M|z-w| \quad \forall z, w \in \bar{D}
$$

If $S=\left\{a_{i}\right\}_{i=1}^{\infty} \in D$ is a discrete sequence with no accumulation points in $D$, let Lip $(S)$ be the set of functions, $g$, defined on $S$ satisfying

$$
\left|g\left(a_{i}\right)-g\left(a_{j}\right)\right| \leqq M\left|a_{i}-a_{j}\right| \quad \forall i, j=1,2, \cdots
$$

We say $S$ is a $\operatorname{Lip}(D)$ interpolating $(L I)$ sequence if the restriction mapping from Lip $(D)$ to Lip $(S)$ given by $f \rightarrow f \mid S$ is surjective. Our aim is to describe some of the properties of such sequences and to give some examples. Specifically we show that an $L I$ sequence must either be a uniformly separated sequence, or the union of two such sequences which approach one another as they tend to $\partial D$.

If $f \in \operatorname{Lip}(D)$ let $M_{f}=\operatorname{Inf}\{M:|f(z)-f(w)| \leqq M|z-w| \forall z, w \in \bar{D}\}$. $M_{f}$ is a pseudo-norm on $\operatorname{Lip}(D)$. If $E$ is a closed subset of $\bar{D}$, let $\operatorname{Lip}_{E}(D)=\{f \in \operatorname{Lip}(D): f(E) \equiv 0\} . \quad M_{f}$ becomes a norm on $\operatorname{Lip}_{E}(D)$ which makes it a Banach space. Let $H^{\infty}(D)$ be the space of bounded analytic function on $D$, for $f \in H^{\infty}(D)$, let $\|f\|=\operatorname{Sup}\{|f(z)|: z \in D\}$. $H^{\infty}(D)$ is related to $\operatorname{Lip}(D)$ by the following:

(1) $f \in \operatorname{Lip}(D)$ iff $f^{\prime} \in H^{\infty}(D)$ in which case $M_{f}=\left\|f^{\prime}\right\|$.

If $S \subset \bar{D}$ is a set with no interior, define

$$
\operatorname{Lip} S=\{f: S \longrightarrow C: \exists M \text { s.t. }|f(z)-f(w)| \leqq M|z-w| \forall z, w \in S\} .
$$

If $E$ is a closed subset of $\bar{S}$, let $\operatorname{Lip}_{E}(S)=\{f \in \operatorname{Lip}(S): f(z) \rightarrow 0$ as $z \rightarrow E$ in $S$ ). If $f \in \operatorname{Lip}(S)$ define $M_{f}=\operatorname{Inf}\{M:|f(z)-f(w)| \leqq$ $M|z-w| \forall z, w \in S\}$. Again we see that $M_{f}$ makes $\operatorname{Lip}_{E}(S)$ into a Banach space. We will say $S$ is a $\operatorname{Lip}(D)$ interpolating $(L I)$ set if the restriction map, $R: f \rightarrow f \mid S$ is a surjection from Lip $(D)$ onto Lip $(S)$. Similarly if $E \subset \bar{S}$ is closed, $S$ will be ealled a $\operatorname{Lip}_{E}(D)$ interpolating $\left(\mathrm{L}_{E} I\right)$ set if $R$ is a surjection from $\operatorname{Lip}_{E}(D)$ onto $\operatorname{Lip}_{E}(S)$. Clearly if $S$ is an $L I$ set, then $\bar{S}$ is an $L I$ set and $S$ is an $L_{E} I$ set for all closed $E \subset \bar{S}$. If $E$ is finite, then $S$ is an $L I$ set iff $S$ is an $L_{E} I$ set.

Proposition 1. If $S$ is an LI set, there exists a constant $m_{S}>0$ 
such that for every $F \in \operatorname{Lip}(S)$ there exists $f \in \operatorname{Lip}(D)$ such $M_{f} \leqq m_{S} M_{F}$ and $f \mid S=F$.

Proof. Since $\operatorname{Lip}_{\left\{z_{0}\right\}} S$ and $\operatorname{Lip}_{\left\{z_{0}\right\}} D$ are Banach spaces, the open mapping theorem gives such an $m_{S}$ for $L_{\left|z_{0}\right|} I$ sets. If $F \in \operatorname{Lip}(S)$ then $F-F\left(z_{0}\right) \in \operatorname{Lip}_{\left\{z_{0} \mid\right.} S$ and $M_{F-F\left(z_{0}\right)}=M_{F}$. Therefore there exists $g \in \operatorname{Lip}_{\left\{z_{0}\right\}}(D) M_{g} \leqq m_{S} M_{F}$ and $g \mid S=F-F\left(z_{0}\right)$. Let $f=g+F\left(z_{0}\right)$.

Taylor and Williams [5] and (independently) Korenblum [4] characterized the zero sets of Lip $(D)$, showing that there exists $f \in \operatorname{Lip}(D)$ such that $\bar{S}=\{z \in D: f(z)=0\}$ if and only if

$$
\int_{0}^{2 \pi} \log \left(d\left(e^{i \theta}\right)\right) d \theta>-\infty \text { where } d\left(e^{i \theta}\right) \text { is the }
$$

(Euclidean) distance from $e^{i \theta}$ to $\bar{S}$

and

$$
S \cap D=\left\{z_{i}\right\}_{i=1}^{\infty} \quad \text { where } \quad \sum_{i=1}^{\infty} 1-\left|z_{i}\right|<\infty
$$

Proposition 2. If $S$ is LI then $\exists f \in \operatorname{Lip}(D)$ such that $f \not \equiv 0$ but $f(S) \equiv 0$. Hence $S$ satisfies (2) and (3).

Proof. Let $z_{0} \in \bar{D} \backslash \bar{S}$ then the distance, $d\left(z_{0}, \bar{S}\right)$, between $z_{0}$ and $S$ must be bounded away from zero. Consequently $F(z)=1 /\left(z-z_{0}\right) \epsilon$ $\operatorname{Lip}(S)$. So there exists $g \in \operatorname{Lip}(D)$ s.t. $g(z)=1 /\left(z-z_{0}\right)$ for all $z \in S$. Clearly if $f(z)=1-\left(z-z_{0}\right) g(z)$, then $f \in \operatorname{Lip}(D), f\left(z_{0}\right)=1$, while $f(S) \equiv 0$.

We are interested primarily in the case where $S=\left\{a_{i}\right\}_{i=1}^{\infty}$ is a sequence in $D$, and from now on we will always assume $S$ is such a sequence. We relate $L I$ sequences to interpolating sequences for $H^{\infty}(D)$.

If $z, w \in D$, we define the pseudo-hyperbolic distance, $\rho(z, w)=$ $|(z-w) /(1-z \bar{w})|$. If $S=\left\{a_{i}\right\}_{i=1}^{\infty}$, let $B_{S}$ be the Blaschke product with zeros precisely at $a_{i}=1,2 \cdots . S$ is interpolating for $H^{\infty}(D)$ if the evaluation mapping from $H^{\infty}(D)$ to $l^{\infty}$ given by $f \rightarrow\left\{f\left(a_{i}\right)\right\}_{i=1}^{\infty}$ is surjective. A well known theorem of L. Carleson [1] is that $S$ is interpolating for $H^{\infty}(D)$ iff it is uniformly separated (US), i.e., there exists a constant $m$ such that

$$
\prod_{\substack{i \neq j \\ i \neq 1}}^{\infty} \rho\left(a_{i}, a_{j}\right)>\frac{1}{m} \text { for all } j \text {. }
$$

We call the constant $m$ in the above definition, a US bound on $S$. 
THEOREM 1. If $S$ is LI then either

(a) $S$ is US or

(b) $S$ is not US but $S=S_{1} \cup S_{2}$ where $S_{1}=\left\{b_{i}\right\}_{i=1}^{\infty}, S_{2}=\left\{c_{i}\right\}_{\imath=1}^{\infty}$ are both US and $\operatorname{Inf}_{i}\left\{\rho\left(b_{\imath}, c_{i}\right): b_{i} \neq c_{\imath}\right\}=0$.

REMARKS. In case (b) we allow for the possibility that $b_{\imath}=c_{i}$ for some (possibly infinitely many) but not all indeces $i$.

Lemma 1. Suppose $T=\left\{d_{j}\right\}_{j=1}^{\infty}$ and suppose there exists a nonzero function $f \in \operatorname{Lip}(D)$ which vanishes on $T$ then

$$
|f(z)| \leqq M_{f}\left|z-d_{j}\right|\left|B_{T /\left\{d_{j}\right\}}(z)\right| \quad \forall j=1,2, \cdots .
$$

Proof. $f \in H^{\infty}(D)$ so $f=F B_{T}$ where $F \in H^{\infty}(D)$. Now fix $j$. $|f(z)|=\left|f(z)-f\left(d_{j}\right)\right| \leqq M_{f}\left|z-d_{j}\right| \forall z \in D$ i.e.,

$$
\left|\frac{F(z)}{1-\bar{d}_{j} z} B_{T /\left\{d_{\jmath}\right\}}(z)\right| \leqq M_{f} \quad \forall z \in D
$$

Since $F(z) /\left(1-\bar{d}_{j} z\right) \in H^{\infty}(D)$ and $\left|B_{T /\left\{d_{j}\right\}}(z)\right|=1$ almost everywhere on $\partial D$ (here we are using (2)) it follows that

$$
\left|\frac{F(z)}{1-\bar{d}_{j} z}\right| \leqq M_{f} \quad \forall z \in D
$$

i.e. $|f(z)| \leqq M_{f}\left|B_{T}(z)\right|\left|1-\bar{d}_{j} z\right|=M_{f}\left|B_{T /\left\{d_{j}\right\}}(z)\right|\left|z-d_{j}\right|$.

Proof of Theorem. If $S$ is $L I$, Proposition 1 implies the existence of a constant $m_{S}$ and function $f_{1}, f_{2}, \cdots, \in \operatorname{Lip}(D)$ such that $M_{f_{\imath}} \leqq m_{S}$ and

$$
f_{i}\left(a_{j}\right)=\left\{\begin{array}{l}
0 \quad \text { if } j \neq i \\
\operatorname{Inf}\left\{\left|a_{i}-a_{k}\right|: \forall k . k \neq i\right\} \quad \text { if } i=j .
\end{array}\right.
$$

Now fix $i$, and let $T=S \backslash\left\{a_{i}\right\}$ then Lemma 1 gives

$$
\left|f_{i}\left(a_{i}\right)\right| \leqq m_{S}\left|B_{T \backslash\left\{a_{j}\right\}}\left(a_{i}\right)\right|\left|a_{i}-a_{j}\right| \text { for all } j \neq i \text {. }
$$

Choose $a_{j}$ so that $\left|a_{i}-a_{j}\right| \leqq 2\left|f_{i}\left(a_{i}\right)\right|$. Then by (4)

$$
1 / 2 m_{S} \leqq \prod_{k \neq i, j} \rho\left(a_{i}, a_{k}\right) \text {. }
$$

If $\operatorname{Inf}\left\{\rho\left(a_{i}, a_{k}\right): i \neq k\right\}=\varepsilon>0$, then by (5),

$$
\prod_{\substack{j=1 \\ j \neq i}}^{\infty} \rho\left(a_{i}, a_{j}\right) \geqq \frac{\varepsilon}{2 m_{S}}
$$

so that $S$ is $U S$. 
Otherwise Inf $\left\{\rho\left(a_{i}, a_{j}\right): \forall i, j, i \neq j\right\}=0$. In that case $S$ is clearly not US.

If $i$ and $j$ are such that $\rho\left(a_{i}, a_{j}\right)<1 /\left(2 m_{s}\right)$ then (5) implies $\rho\left(a_{i}, a_{k}\right) \geqq 1 /\left(2 m_{S}\right), \rho\left(a_{j}, a_{k}\right) \geqq 1 /\left(2 m_{S}\right)$ for $k \neq i, j$. Consequently the relation, $a_{i} \sim a_{j}$ iff $\rho\left(a_{i}, a_{j}\right)<1 /\left(2 m_{s}\right)$ is an equivalence relation on $S$ which partitions $S$ into a collection, $C$, of equivalence classes of no more than two elements each. Let

$$
\begin{aligned}
& S_{1}=\left\{a_{j_{1}}: \exists j_{2} \geqq j_{1} \text { s.t. }\left\{a_{j_{1}}, a_{j_{2}}\right\} \in C\right\} \\
& S_{2}=\left\{a_{j_{2}}: \exists j_{1} \leqq j_{2} \text { s.t. }\left\{a_{j_{1}}, a_{j_{2}}\right\} \in C\right\} .
\end{aligned}
$$

Then for $\alpha=1,2$, if $a_{j_{0}} \in S_{a}$, (5) yields

$$
\prod_{\substack{a_{k \in S_{\alpha}} \\ a_{k} \neq \alpha_{j_{0}}}} \rho\left(a_{k}, a_{j_{0}}\right) \geqq \frac{1}{4 m_{s}^{2}} .
$$

Consequently $S_{1}$ and $S_{2}$ are both $U S$. Renaming the points: $S_{1}=$ $\left\{b_{i}\right\}_{i=1}^{\infty}, S_{2}=\left\{c_{i}\right\}_{i=1}^{\infty}$ so that $\left\{b_{i}, c_{i}\right\} \in C$, we get the desired decomposition.

There remains the question of whether any $L I$ sequences exist. For example, it is possible to construct a US sequence, converging to only one point on $D$, but violating (2). Hence US need not imply $L I$. Theorem 2 and its corollary give some conditions under which $U S$ does imply $L I$.

For fixed $t, 0<t<1$, define the nontangential wedge, $W_{t}=$ $\left\{z \in D:\left(1-\left|z^{2}\right|\right) /\left|1-z^{2}\right|>t\right\} . \quad W_{t}$ is the region lying between two distinct circles with centers on the imaginary axis, which intersect one another at \pm 1 . Let $\hat{W}_{t}=D \cup\left[\left(\bar{D} \backslash \bar{W}_{t}\right)^{*}\right]$ where $\left(^{-}\right)$means closure and ${ }^{*}$ means reflection across the unit circle. Let $\sigma(z)=(1-z) /(1+z)$. $\sigma$ maps $D$ into the right half-plane. It takes $W_{t}$ onto the region lying to the right of both lines, $y= \pm\left(\sqrt{1-t^{2}} / t\right) x$, and it takes $\hat{W}_{t} \backslash \bar{W}_{t}$ onto the region lying between the two lines.

Proposition 3. Suppose $0<t<1$ and $S=\left\{a_{n}\right\}_{n=1}^{\infty} \subset W_{t}$ is US. Then if $g(z)=\left(1-z^{2}\right) B_{S}(z), g \in \operatorname{Lip}(D)$.

We require the following elementary facts:

Lemma 2. If $\Omega \subset C$ is open, and $f \in H^{\infty}(\Omega)$, then for $z \in \Omega$, $\left|f^{\prime}(z)\right| \leqq\|f\| / d(z, \partial \Omega)$, where $d(z, \partial \Omega)$ is the Euclidean distance from $z$ to $\partial \Omega$, and $\|f\|=\operatorname{Sup}\{|f(z)|: z \in \Omega\}$.

This is proved by applying the Cauchy Integral Formula around circles centered at $z$ with radii $\leqq d(z, \partial \Omega)$.

Lemma 3 (Theorem 1 of [2]). If $S$ is US with US bound $1 / \delta$, 
then there exists a constant $\beta, 0<\beta<1$, depending only on $\delta$, such that if $\rho\left(z, a_{n}\right)>\delta / 2$ for all $n,\left|B_{S}(z)\right| \geqq \beta$.

Lemma 4. For any $t, 0<t<1$, and any $\varepsilon, 0<\varepsilon<1$, there exists $s>0$ such that $U_{\varepsilon}\left(W_{t}\right)=\left\{z \in D: \exists w \in W_{t}\right.$ with $\left.\rho(z, w)<\varepsilon\right\} \subset W_{s}$.

Proof of Proposition 3. Assume $S$ has $U S$ bound, $1 / \delta$. We will show $g^{\prime} \in H^{\infty}(D)$. Upon differentiating $g$, we see that it will be sufficient to show $\left(1-z^{2}\right) B_{S}{ }^{\prime}(z)$ is bounded in $D$.

Take $s$ as in Lemma 4 , so that $U_{\delta}\left(W_{t}\right) \subset W_{s}$, whereby $\left|B_{S}(z)\right| \geqq \beta$ for $z \in D \backslash W_{s}$ by Lemma 3. Now if $z \in C \backslash \bar{S}, B_{S}\left(z^{*}\right)=\left(B_{S}(z)\right)^{*}\left({ }^{*}\right.$ still means reflection across $\partial D)$. Hence by the definition of $\hat{W}_{s},\left|B_{S}(z)\right| \leqq$ $1 / \beta$ for $z \in \hat{W}_{s} \mid D$. Since $\left|B_{S}(z)\right| \leqq 1$ for $z \in D$, it follows that $B_{S} \in$ $H^{\infty}\left(\hat{W}_{s}\right)$, and, by Lemma $2,\left|B_{S}^{\prime}(z)\right| \leqq 1 /\left(\beta d\left(z, \partial \hat{W}_{s}\right)\right)$ for all $z \in \hat{W}_{s}$. The proposition will be proved once we show $d\left(z, \partial \hat{W}_{s}\right) \geqq k\left|1-z^{2}\right|$ for all $z \in D$ and some constant, $k$.

If $z \in D$, let $w_{z} \in \partial \hat{W}_{s}$ be such that $\left|w_{z}-z\right|=d\left(z, \partial \hat{W}_{s}\right)$. Clearly, if $\operatorname{Re}(z) \geqq 0$, then $\operatorname{Re}\left(w_{z}\right) \geqq 0$. Recalling the map $\sigma(z)=(1-z) /(1+z)$, we see that

$$
2\left|z-w_{z}\right| \geqq\left|\sigma(z)-\sigma\left(w_{z}\right)\right| \geqq \sin \theta|\sigma(z)|
$$

where $\theta$ is the angle between the lines $y= \pm\left(\sqrt{1-s^{2}} / s\right) x$ and the imaginary axis. In fact, $\sin \theta=\sqrt{1-s^{2}}$. Therefore, if $z \in D$ and $\operatorname{Re}(z) \geqq 0$,

$$
2 d\left(z, \partial \hat{W}_{s}\right) \geqq \sqrt{1-s^{2}}|\sigma(z)| \geqq(1 / 4) \sqrt{1-s^{2}}\left|1-z^{2}\right| .
$$

Since $\hat{W}_{s}$ and $D$ are symmetric about $\operatorname{Re}(z)=0$ the desired inequality holds for all $z \in D$.

Corollary. If $S_{1}, S_{2} \subset W_{t}$ and $S_{1}$ and $S_{2}$ are both US then

$$
\left(1-z^{2}\right) B_{S_{1} \cup S_{2}}(z) \in \operatorname{Lip}(D) \text {. }
$$

TheOREM 2. Suppose $0<t<1, S=\left\{a_{n}\right\}_{n=1}^{\infty} \subset W_{t}$, and $S$ is US. Then

(a) $S$ is $L I$.

(b) There exists a sequence $S_{1}=\left\{b_{n}\right\}_{n=1}^{\infty}$ such that $S_{1}$ is US, $S \cup S_{1}$ is $L I$, and $\rho\left(a_{n}, b_{n}\right) \rightarrow 0$ as $n \rightarrow \infty$

(c) If $h \in \operatorname{Lip}(S)$ and $\left\{\lambda_{n}\right\}_{n=1}^{\infty} \in l^{\infty}$ then there exists $f \in \operatorname{Lip}(D)$ such that $f \mid S=h$ and $f^{\prime}\left(a_{n}\right)=\lambda_{n}$ for all $n$.

The first of the folloging two lemmas is a straightforward calculation with infinite products; the second is due to J.P. Earl. 
Lemma 5. Suppose $S=\left\{a_{n}\right\}_{n=1}^{\infty} \subset D$ is US with US bound $1 / \delta$. If $\rho\left(a_{n}, z_{n}\right)<1 / 3 \delta$, then $\left\{z_{n}\right\}_{n=1}^{\infty}$ is US, and there exists a constant, $C_{\delta}$ such that $\left|B_{S}\left(z_{n}\right)\right| \geqq C_{\delta} \rho\left(a_{n}, z_{n}\right)$.

Lemma 6 (see [3]). Suppose $S=\left\{\alpha_{n}\right\}_{n=1}^{\infty} \subset D$ is US, then there exists a constant $\eta_{0}>0$ such that for any $\eta, 0<\eta<\eta_{0}$, and any sequence $\left\{\lambda_{n}\right\}_{n=1}^{\infty} \in l^{\infty}$, there exists a (US) sequence, $S^{\prime}=\left\{z_{n}\right\}_{n=1}^{\infty} \subset D$ and $a$ complex constant, $Q$, such that $\rho\left(a_{n}, z_{n}\right)<\eta$ and $Q B_{S^{\prime}}\left(a_{n}\right)=\lambda_{n}$ for all $n$.

Proof of Theorem 2. Assume $S$ has $U S$ bound $1 / \delta$.

a) It is sufficient to show $S$ is $L_{ \pm 1} I$. So let $h \in \operatorname{Lip}_{ \pm 1} S$. This implies $\left|h\left(a_{n}\right)\right| /\left|1-a_{n}^{2}\right| \leqq M_{h}$. If $\eta<\operatorname{Min}\left\{1 / 3 \delta, \eta_{0}\right\}$ (where $\eta_{0}$ is as in Lemma 6), there exists a complex number $Q$ and a US sequence $S^{\prime}=\left\{c_{n}\right\}_{n=1}^{\infty}$ such that $\rho\left(a_{n}, c_{n}\right)<\eta$ and $Q B_{S^{\prime}}\left(a_{n}\right)=h\left(a_{n}\right) /\left(1-a_{n}^{2}\right)$ for all $n$. By Lemma 4 and proposition 3 , if $f(z)=Q\left(1-z^{2}\right) B_{S_{1}}(z)$, $f \in \operatorname{Lip}(D)$ and $f \mid S=h$. Therefore, $S$ is $L I$.

b) Define $b_{n}$ as follows. If $1-\left|a_{n}\right|<\delta / 3$, choose $b_{n}$ so that $\left|b_{n}-a_{n}\right| \leqq 1 / 2\left(1-\left|a_{n}\right|\right)^{2}$. Otherwise, let $b_{n}=a_{n}$.

$$
\rho\left(a_{n}, b_{n}\right) \leqq\left|b_{n}-a_{n}\right| /\left(1-\left|a_{n}\right|\right)<1-\left|a_{n}\right| .
$$

Moreover, $\left|1 \pm b_{n}\right| \geqq\left|1 \pm a_{n}\right|-\left|a_{n}-b_{n}\right| \geqq 1 / 2\left(1-\left|a_{n}\right|\right)$. So $\left|1-b_{n}^{2}\right| \geqq 1 / 4\left(1-a_{n}\right)^{2} \geqq 12\left|a_{n}-b_{n}\right|$.

Consequently,

$$
\frac{\left|b_{n}-a_{n}\right|}{\rho\left(a_{n}, b_{n}\right)\left|1-b_{n}^{2}\right|}=\frac{\left.|1-| b_{n}\right|^{2}+b_{n}\left(\bar{b}_{n}-\bar{a}_{n}\right) \mid}{\left|1-b_{n}^{2}\right|} \leqq 3 .
$$

Now (6) and Lemmas 4 and 5 imply $S_{1}=\left\{b_{n}\right\}_{n=1}^{\infty}$ is $U S, S_{1} \subset W_{s}$ for some $s>0$, and $\rho\left(a_{n}, b_{n}\right) \rightarrow 0$, so $S \cup S_{1}$ is not $U S$.

If $h \in \operatorname{Lip}_{ \pm 1}\left(S \cup S_{1}\right)$, by part (a), we have $F \in \operatorname{Lip}(D)$ such that $F|S=h| S$. Let $h_{1}=h-F \mid\left(S \cup S_{1}\right)$. Then $\left|h_{1}\left(b_{n}\right)\right|=\mid h_{1}\left(b_{n}\right)-$ $h_{1}\left(a_{n}\right)\left|\leqq M_{h_{1}}\right| a_{n}-b_{n} \mid$. Lemma 5 and $(7)$ give $\left|h_{1}\left(b_{n}\right)\right| /\left|\left(1-b_{n}^{2}\right) B_{S}\left(b_{n}\right)\right| \leqq$ $3 M_{h_{1}} / C_{\dot{o}}$. By Lemmas 4,5 , and 6 , there is a constant $Q^{\prime}$ and a US sequence, $S_{3}$ contained in a wedge, such that $Q^{\prime} B_{S_{3}}\left(b_{n}\right)=h_{1}\left(b_{n}\right) /(1-$ $\left.b_{n}^{2}\right) B_{S}\left(b_{n}\right)$ for all $n$. Let $f(z)=F(z)+Q^{\prime}\left(1-z^{2}\right) B_{S_{3} \cup s}(z)$. Then $f \in$ $\operatorname{Lip}(D)$ and $f \mid\left(S \cup S_{1}\right)=h$.

c) We note that $B_{S}^{\prime}\left(a_{n}\right)=B_{S \backslash\left\{a_{n}\right)}\left(a_{n}\right) /\left(1-\left|a_{n}\right|^{2}\right)$ so that if $\left\{\gamma_{n}\right\}_{n=1}^{\infty} \in l^{\infty}$ and $\Gamma=\operatorname{Sup}_{n}\left|\gamma_{n}\right|$, then $\left|\gamma_{n} /\left(1-a_{n}^{2}\right) B_{S}^{\prime}\left(a_{n}\right)\right| \leqq \Gamma / \delta$. Applying Lemmas 4, 5, and 6 and the corollary to Proposition 3, we have a constant $Q^{\prime \prime}$, a $U S$ sequence $S^{\prime \prime}$ (contained in a wedge) such that if $g(z)=Q^{\prime \prime}\left(1-z^{2}\right) B_{S \cup S^{\prime \prime}}(z), g \in \operatorname{Lip}(D), g\left(a_{n}\right)=0$, and $g^{\prime}\left(a_{n}\right)=\gamma_{n}$ for all $n$.

Finally, if $h \in \operatorname{Lip}(S)$ and $\left\{\lambda_{n}\right\}_{n=1}^{\infty} \in l^{\infty}$, by part (a) there exists 
$G \in \operatorname{Lip}(D)$ such that $G \mid S=h$. Letting $\gamma_{n}=\lambda_{n}-G^{\prime}\left(a_{n}\right)$, and obtaining $g$ as above, we see that $f=G+g$ performs the desired interpolation.

We note that for $0<t<1$, if $\Phi_{t}=\sigma\left((\sigma(z))^{a}\right)$, where $\alpha=(2 / \pi)$ $\arccos (t), \Phi_{t}: D \rightarrow W_{t}$ and $\Phi_{t}: \hat{W}_{s} \rightarrow D$ for an appropriately chosen $s$.

Corollary. Suppose $S=\left\{a_{n}\right\}_{n=1}^{\infty} \subset D$ and there exists $t, 0<t<1$, such that $\Phi_{t}(S)=\left\{\Phi_{t}\left(a_{n}\right)\right\}_{n=1}^{\infty}$ is US. Then $S$ is LI.

Proof. The hypothesis guarantees that $\partial D \cap \bar{S} \subset\{ \pm 1\}$ and $S$ is US. Let $h \in \operatorname{Lip}_{ \pm 1} S$, then $h\left(a_{n}\right) /\left(1-a_{n}^{2}\right) \in l^{\infty}$ so there exists a constant $Q$ and a $U S$ sequence of points, $S^{\prime}$, near $\Phi_{t}(S)$ such that $Q B_{S^{\prime}}\left(\Phi_{t}\left(a_{n}\right)\right)=$ $h\left(a_{n}\right) /\left(1-a_{n}^{2}\right)$. A straight forward calculation, or an appeal to Lemma 2 , shows that if $f(z)=\left(1-z^{2}\right) Q B_{S}, \circ \Phi_{t}(z)$, then $f \in \operatorname{Lip}(D)$. Clearly $f\left(a_{n}\right)=h\left(a_{n}\right)$.

REmaRks. (1) Call any region in $D$ which lies between two circular arcs that intersect twice on $\partial D$ a nontangential wedge. Any such wedge can be mapped into one of the form $W_{t}$ by a Mobious transformation. Since composition with Mobious transformations preserves Lip $(D)$, it follows that Theorem 2 remains true for sequences contained in a finite union of arbitrary nontangential wedges.

(2) By noting that $S$ is $H^{\infty}$ interpolating for $\hat{W}_{t}$ in Theorem 2, and applying Lemma 2, we can eliminate the need for Lemma 6, simplifying (slightly) the proof of Theorem 2. On the other hand, the argument presented here shows that as in the $H^{\infty}$ case, Lipschitz interpolation can be performed by (somewhat modified) Blaschke products.

(3) The corollary to Theorem 2 enables one to construct tangential $L I$ sequences by taking a $U S$ sequence $S_{1} \subset W_{t}$ which is contained in no $W_{s}$ for $s>t$, and letting $S=\Phi_{t}^{-1}\left(S_{1}\right)$.

For certain types of tangential sequences we can obtain conditions b) and c) of Theorem 2.

Definition. If $0<c<\infty$, let $\Omega_{c}=\left\{z \in D:\left(1-|z|^{2}\right) /|1-z|^{2}>c\right\}$. $\Omega_{c}$ is a disk in $D$, tangent to $\partial D$ at 1 (with radius $1 / 1+c$ ).

THEOREM 3. Suppose $S=\left\{a_{n}\right\}_{n=1}^{\infty} \subset \Omega_{c_{1}} \backslash \Omega_{c_{2}}$ is US $\left(0<c_{1}<c_{2}\right)$. Then

(a) If $S$ is LI, statements b) and c) of Theorem 2 hold. Otherwise,

(b) There exists a sequence $S_{1}=\left\{b_{n}\right\}_{n=1}^{\infty}$ with $\rho\left(a_{n}, b_{n}\right) \rightarrow 0$, such that if $h \in \operatorname{Lip}_{\bar{S}}\left(S_{1} \cup S\right)$, there exists $f \in \operatorname{Lip}(D)$ such that $f \mid\left(S_{1} \cup S\right)=h$. 
(c) If $\left\{\lambda_{n}\right\}_{n=1}^{\infty} \in l^{\infty}$ there exists $f \in \operatorname{Lip}(D)$ such that $f\left(a_{n}\right)=0$ and $f^{\prime}\left(a_{n}\right)=\lambda_{n}$ for all $n$.

The proof of Theorem 3 is essentially the same as that of parts (b) and (c) of Theorem 2, once we have the following.

Lemma 4a. For fixed $c>0$ and $\varepsilon>0$, there exists $d, 0<d<c$, such that $U_{\varepsilon}\left(\Omega_{c}\right)=\left\{z \in D: \exists w \in \Omega_{c}\right.$ with $\left.\rho(z, w)<\varepsilon\right\} \subseteq \Omega_{d}$.

Proposition 3a. If $S_{1}$ and $S_{2} \subset \Omega_{c}$ are US then $(1-z)^{2} B_{S_{1} \cup S_{2}}(z) \in$ $\operatorname{Lip}(D)$.

Proof. It is sufficient to show $(1-z)^{2} B_{S_{j}}(z) \in \operatorname{Lip}(D)$ for $j=1,2$. Lemmas 3 and $4 a$ enable us to take $d<c$ such that $\left|B_{S_{j}}(z)\right|>\beta$ for $z \in D \backslash \Omega_{d}$. Since composition with Mobious transformation preserves $\operatorname{Lip}(D)$, we may as well assume that $d=1$. If $\hat{\Omega}_{1}$ is the half-plane, $\{z: \operatorname{Re}(z)<1\}$, it is clear that $\widehat{\Omega}_{1} \backslash \bar{D}=\left(D \backslash \Omega_{\Omega_{1}}\right)^{*}$. Simple arithematic shows that for $z \in \mathrm{D}, d\left(z, \partial \hat{\Omega}_{1}\right) \geqq 1 / 2|1-z|^{2}$. The arguments of Proposition 3 can now be applied.

Finally, we note that the problem of describing $L I$ sequences can be broken into two parts: describing $L I$ sets on $\partial D$, and describing sequences, $S$, which are $L_{\bar{S} \cap \partial D} I$ sequences.

Proposition 4. Let $S=\left\{a_{n}\right\}_{n=1} \subset D$ and let $E=\bar{S} \cap \partial D$. Then $S$ is an $L I$ sequence iff $S$ is an $L_{E} I$ sequence and $E$ is an $L I$ set.

Proof. Suppose $S$ is $L I$. Then $S$ is clearly $L_{E} I$. Let $F \in \operatorname{Lip}(E)$. By a theorem of Valentine (see [6]), $F$ can be extended to $G \in \operatorname{Lip}(\bar{S})$. Hence there exists $g \in \operatorname{Lip}(D)$ such that $g|S=G| S$. Since $g$ is uniformly continuous, it is clear that $g \mid E=F$.

Conversely, if $S$ is an $L_{E} I$ sequence, and $E$ is an $L I$ set, let $h \in \operatorname{Lip}(S) . \quad h$ can be extended to $F \in \operatorname{Lip}(\bar{S})$. Hence there exists $g \in \operatorname{Lip}(D)$ such that $g|E=F| E$. If $H=h-g \mid S$, then $H \in \operatorname{Lip}_{E}(S)$ and there exists $G \in \operatorname{Lip}(D)$ such that $G \mid S=H . \quad(G+g) \in \operatorname{Lip}(D)$ and $(G+g) \mid S=h$.

REMARKs. (1) Theorems 1 and 2 should be compared with the results of S. A. Vinogradov [7] which deal with nontangential sequences for functions with derivatives in $H^{1}(D)$. In this case, US is necessary and sufficient for the appropriate interpolation problem.

(2) We are indebted to the referee whose remarks resulted in greatly simplified proofs of Propositions 3 and $3 \mathrm{a}$. He also pointed out the existence of tangential $L I$ sequences. 


\section{REFERENCES}

1. L. Carleson, An interporation problem for bounded analytic funtions, Amer. J. Math. 80 (195̃8), 921-930.

2. J. Cima and P. Colwell, Blashke quotients and dormality, Proc. Amer. Math. Soc. 19 (1968), 796-798.

3. J.P. Earl, On the interpolation of bounded sequences by bounded functions, J. London Math. Soc. (2), 2 (1970), 544-548.

4. B. Korenblum, Functions holomorphic in a disk and smooth in its closure, Soviet Math. Doklady, Vol. 12 (1971), no. 5, 1312-1315.

5. B. A. Taylor and D. L. Williams, Zeros of Lipschitz functions analytic in the disc, Michigan Math. J. 18 (1971), 129-139.

6. F.A. Valentine, A Lipschitz condition preserving extension for a vector valued function, Amer. J. Math. 67 (1945), 83-93.

7. S. A. Vinogradov, Interpolation and zeros of power series with a sequence of coefficients from $l^{p}$, Soviet Math. Doklady, 6 (1965) 57-60.

Received November 4, 1974. This work has been (partially) supported by NSF Grant GP-42223.

UNIVERSITY OF MiChIGAN 



\section{PACIFIC JOURNAL OF MATHEMATICS}

EDITORS

RICHARD ARENS (Managing Editor)

University of California

Los Angeles, California 90024

R. A. BEAUMONT

University of Washington

Seattle, Washington 98105
J. DugundJI

Department of Mathematics

University of Southern California

Los Angeles, California 90007

D. Gilbarg and J. Milgram

Stanford University

Stanford, California 94305

\section{ASSOCIATE EDITORS}

E. F. BECKENBACH

B. H. NeumanN

F. WOLF

K. YosHIDA

\section{SUPPORTING INSTITUTIONS}

UNIVERSITY OF BRITISH COLUMBIA

UNIVERSITY OF SOUTHERN CALIFORNIA

CALIFORNIA INSTITUTE OF TECHNOLOGY

UNIVERSITY OF CALIFORNIA

STANFORD UNIVERSITY

UNIVERSITY OF TOKYO

MONTANA STATE UNIVERSITY

UNIVERSITY OF UTAH

UNIVERSITY OF NEVADA

WASHINGTON STATE UNIVERSITY

NEW MEXICO STATE UNIVERSITY

UNIVERSITY OF WASHINGTON

OREGON STATE UNIVERSITY

UNIVERSITY OF OREGON

OSAKA UNIVERSITY

AMERICAN MATHEMATICAL SOCIETY
NAVAL WEAPONS CENTER

Printed in Japan by International Academic Printing Co., Ltd., Tokyo, Japan 


\section{Pacific Journal of Mathematics}

\section{Vol. 63, No. $1 \quad$ March, 1976}

Ralph Artino, Gevrey classes and hypoelliptic boundary value problems ....... 1

B. Aupetit, Caractérisation spectrale des algèbres de Banach commutatives .... 23

Leon Bernstein, Fundamental units and cycles in the period of real quadratic

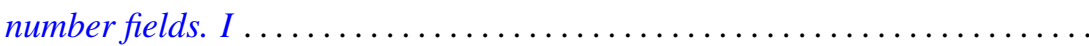

Leon Bernstein, Fundamental units and cycles in the period of real quadratic number fields. II.................................... 63

Robert F. Brown, Fixed points of automorphisms of compact Lie groups ........

Thomas Ashland Chapman, Concordances of noncompact Hilbert cube

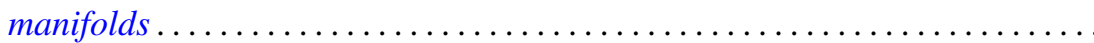

William C. Connett, V and Alan Schwartz, Weak type multipliers for Hankel

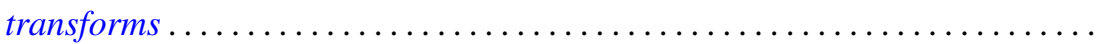

John Wayne Davenport, Multipliers on a Banach algebra with a bounded approximate identity .....................................

Gustave Adam Efroymson, Substitution in Nash functions ................ 137

John Sollion Hsia, Representations by spinor genera ..................

William George Kitto and Daniel Eliot Wulbert, Korovkin approximations in

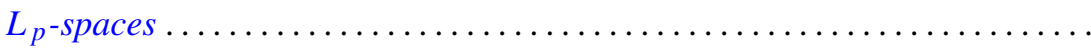

Eric P. Kronstadt, Interpolating sequences for functions satisfying a Lipschitz. condition ...........................................

Gary Douglas Jones and Samuel Murray Rankin, III, Oscillation properties of certain self-adjoint differential equations of the fourth order...

Takaŝi Kusano and Hiroshi Onose, Nonoscillation theorems for differential

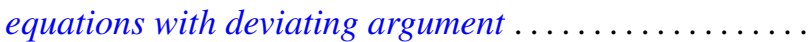

David C. Lantz, Preservation of local properties and chain conditions in commutative group rings. ...

Charles W. Neville, Banach spaces with a restricted Hahn-Banach extension property....

Norman Oler, Spaces of discrete subsets of a locally compact group ...

Robert Olin, Functional relationships between a subnormal operator and its minimal normal extension.

Thomas Thornton Read, Bounds and quantitative comparison theorems for nonoscillatory second order differential equations ...... .

Robert Horace Redfield, Archimedean and basic elements in completely distributive lattice-ordered groups...

Jeffery William Sanders, Weighted Sidon sets

Aaron R. Todd, Continuous linear images of pseudo-complete linear topological spaces.

J. Jerry Uhl, Jr., Norm attaining operators on $L^{1}[0,1]$ and the Radon-Nikodým property.

William Jennings Wickless, Abelian groups in which every endomorphism is a left multiplication. 